\title{
The coming crisis
}

\section{Obtaining care for the growing burden of neurodegenerative conditions}

6

E. Ray Dorsey, MD, MBA

Benjamin P. George, $\mathrm{MPH}$

Bruce Leff, MD

Allison W. Willis, MD

Correspondence to

Dr. Dorsey:

ray.dorsey@jhmi.edu
Editorial, page 1916

Supplemental data at www.neurology.org

\section{ABSTRACT}

As the US population ages, the burden of neurodegenerative disorders, including Alzheimer disease and Parkinson disease, will increase substantially. However, many of these patients and their families currently do not receive neurologic care. For example, a recent study found that over $40 \%$ of Medicare beneficiaries with an incident Parkinson disease diagnosis did not receive neurologist care early after diagnosis and those who did not were more likely to fracture a hip, be placed in a nursing home, and die. While geography, age, race, and sex likely contribute to these observed disparities in care and outcomes, a large barrier may be Medicare's reimbursement policies, which value procedures over care. With further reductions in Medicare reimbursement constantly on the horizon, the devaluing of clinical care will likely continue. Rather than guaranteeing access to care, Medicare's reimbursement policies may increasingly be an impediment to care. Neurology ${ }^{\circledR}$ 2013;80:1989-1996

\section{GLOSSARY}

PD $=$ Parkinson disease

As baby boomers age in the United States, the burden of neurodegenerative conditions among Medicare beneficiaries will increase substantially. For example, from 2010 to 2030, the number of individuals 65 years or older with Parkinson disease (PD) will increase by 77\% from 300,000 to 530,000 (figure 1A). ${ }^{1}$ For Alzheimer disease, the most common neurodegenerative condition, the number of individuals affected will increase by more than $50 \%$ from 5.1 million in 2010 to 7.7 million in 2030 (figure 1B). ${ }^{2}$ The increase in these and other neurodegenerative conditions will drive demand for neurologic care.

NEUROLOGIC CARE UTILIZATION IS LIMITED However, many Medicare beneficiaries with neurodegenerative conditions currently are not utilizing neurologic care. A recent report found that $42 \%$ of Medicare beneficiaries with an incident diagnosis of PD do not receive care from a neurologist within the first 4 years after diagnosis. ${ }^{3}$ The lack of neurologic care may have health consequences. ${ }^{4}$ Beneficiaries with PD who did not see a neurologist were $14 \%$ more likely to fracture a hip, $21 \%$ more likely to be placed in a skilled nursing facility in the first year after diagnosis, and $22 \%$ more likely to die within 6 years of diagnosis. ${ }^{3}$ While confounding by health state may explain a portion of these results and causative links remain to be established, a follow-up investigation found that patients with PD who were treated by a neurologist compared to a generalist were less likely to have hospitalizations related to PD. ${ }^{5}$ Other studies have found that adherence to care quality indicators ${ }^{6}$ and patient satisfaction ${ }^{7}$ are increased among patients who see a PD specialist. For other chronic conditions, the involvement of specialists is associated with improved process measures and clinical outcomes in asthma, ${ }^{8}$ cardiac disease, ${ }^{9}$ and diabetes. ${ }^{10}$

Utilization of services is an outcome indicator of access, which is influenced by geographical, social, and organizational factors. ${ }^{11,12}$ The geographical distribution of physicians affects access to medical care, as demonstrated by Health Professional Shortage Areas, which lack both primary care physicians and specialists. Like other specialists, neurologists tend to cluster in urban areas and along the coasts. For example, the number of neurologists per capita in Massachusetts is more than 4 times that of Wyoming. ${ }^{13}$ However, areas with the greatest number of neurologists have a large proportion of Medicare beneficiaries with PD who do not receive care from a neurologist (figure 2). These findings suggest that factors other than geography need to be considered.

Social factors, including sex, race, and age, also influence who receives neurologic care. Nonwhites, women, and the most elderly with PD are less likely to obtain specialist care. ${ }^{3}$ For example, African Americans are 4 times less

From the Departments of Neurology (E.R.D.) and Medicine (B.L.), Johns Hopkins Medicine, Baltimore, MD; University of Rochester School of Medicine and Dentistry (B.P.G.), Rochester, NY; and Department of Neurology (A.W.W.), Washington University School of Medicine, St. Louis, MO. Go to Neurology.org for full disclosures. Funding information and disclosures deemed relevant by the authors, if any, are provided at the end of the article. 
Figure 1 Projected number of Medicare beneficiaries with Parkinson disease and Alzheimer disease in millions (2010-2030)

A

Medicare beneficiaries
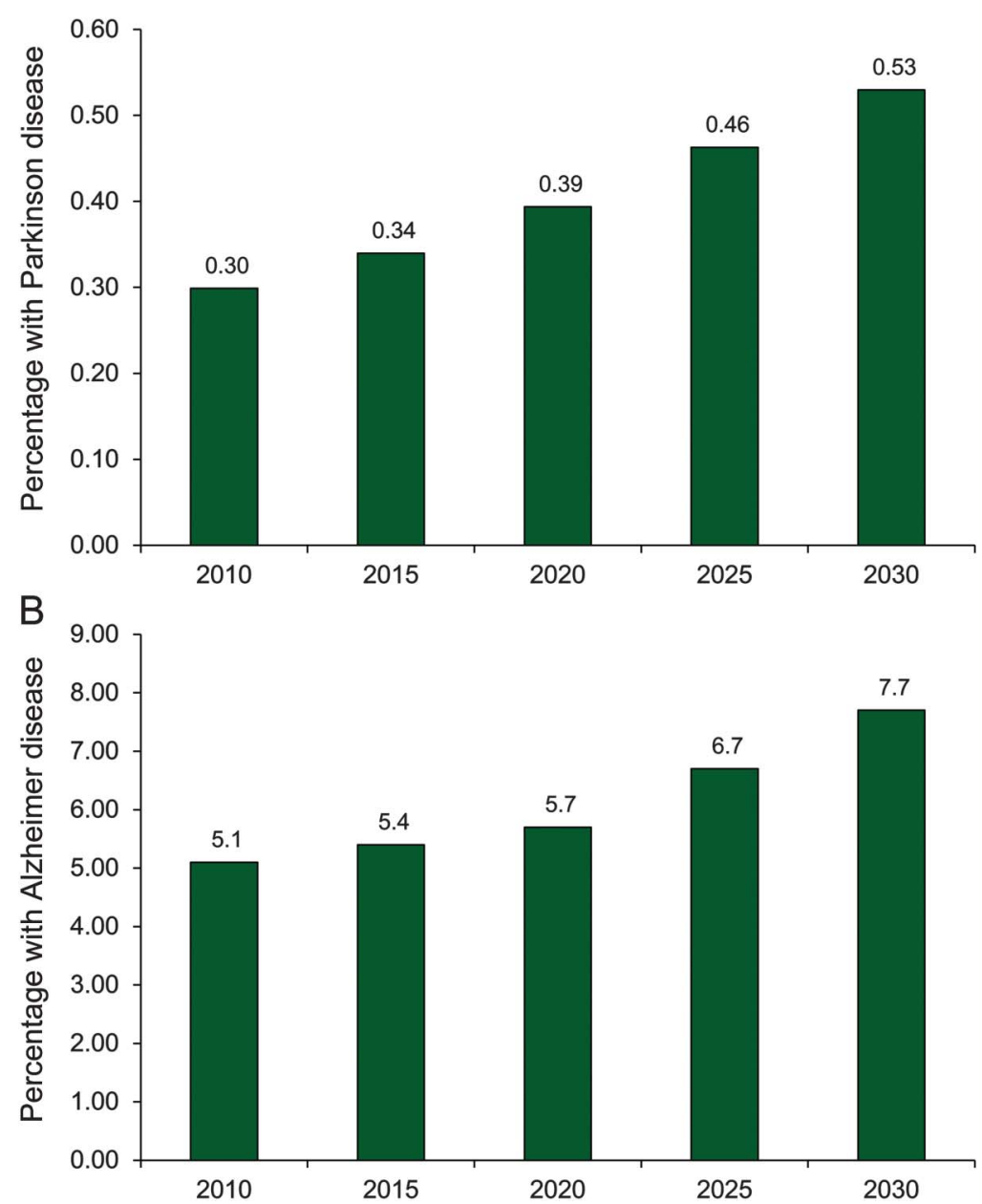

(A) Parkinson disease. (B) Alzheimer disease. Data adapted from Dorsey et al., 2007, ${ }^{1}$ and Hebert et al., 2003. ${ }^{2}$

likely than whites to receive any treatment for $\mathrm{PD}$, and clinical trials, generally at specialist centers, favor younger, educated, white men. ${ }^{14}$ The lack of African American and female neurologists-fewer than $2 \%$ of US neurologists are African American and fewer than $30 \%$ are women ${ }^{13}$ - may also contribute to diminished access for many.

Organizational factors may also contribute to the low utilization of neurologists. Many primary care physicians prefer to manage neurologic disorders themselves. ${ }^{15} \mathrm{In}$ one study, when confronted with a patient with PD or dementia, more than half of primary care physicians indicated a preference to manage the patient alone or just curbside a specialist. By contrast, more than $90 \%$ of neurologists thought that the patient should be referred to a specialist. ${ }^{15}$ Primary care physicians may be quite successful in managing these disorders. For example, a randomized controlled trial of a collaborative care model led by primary care physicians improved the quality of care among individuals with dementia. ${ }^{16}$ This model, which included a primary care physician and a geriatric care manager, was also supported by weekly meetings with specialists, including a geriatrician and a geriatric psychiatrist. ${ }^{16}$

MEDICARE'S REIMBURSEMENT POLICIES MAY BE CONTRIBUTING TO LOW UTILIZATION AND LIMITED ACCESS While these geographic, social, and organizational factors are important, they are insufficient to explain the widespread lack of access, so alternative causes must be sought and actionable hypotheses considered. Insurance is among the most important determinants of access for patients, ${ }^{17}$ and Medicare was explicitly designed to guarantee that older Americans have access to health care at a time when half did not. ${ }^{18}$ However, the lack of access to neurologic care is occurring among individuals with health insurance.

The lack of utilization may not be due to financial factors on the part of patients but rather financial factors affecting physicians. An alternative explanation for the lack of utilization to neurologists is that Medicare's reimbursement for care for chronic conditions like Alzheimer disease and PD is simply too low.

Shortages can arise in a market when the price for a good or service is below the equilibrium price or price where the quantity demanded for a particular good or service is equal to the quantity supplied of that good or service. Because Medicare, through the Centers for Medicare \& Medicaid Services, and not the market sets the price for physician (and other) services covered by Medicare, that price could be greater than, equal to, or less than the equilibrium price. When a price is set below the equilibrium price, a shortage can result (figure 3).

As figure 3 depicts, in a free market, the price of a good or service is the point at which the quantity demanded of a good or service equals the quantity supplied. However, when the government (or any organization) sets the price of a good or service below the market equilibrium price, the quantity demanded of that good or service exceeds the quantity supplied, resulting in a shortage. The situation for medical services is complicated by the fact that because of insurance the price faced by patients (e.g., a copayment) is less than the actual price of the service, but the general principle still applies. ${ }^{19}$ In the case of neurologic care for patients with PD, if Medicare sets reimbursement rates below the market equilibrium price for that service, the quantity of those services demanded would exceed the quantity supplied.

Determining whether Medicare reimbursement for a particular good or service is below the market equilibrium rates is difficult, but there are clues. The first is that shortages are generally associated with increased wait times, and according to the American Academy of Neurology Medical Economics Issues Survey, the wait time to see a neurologist is about double that to see a cardiologist. ${ }^{\mathrm{el}}$ 


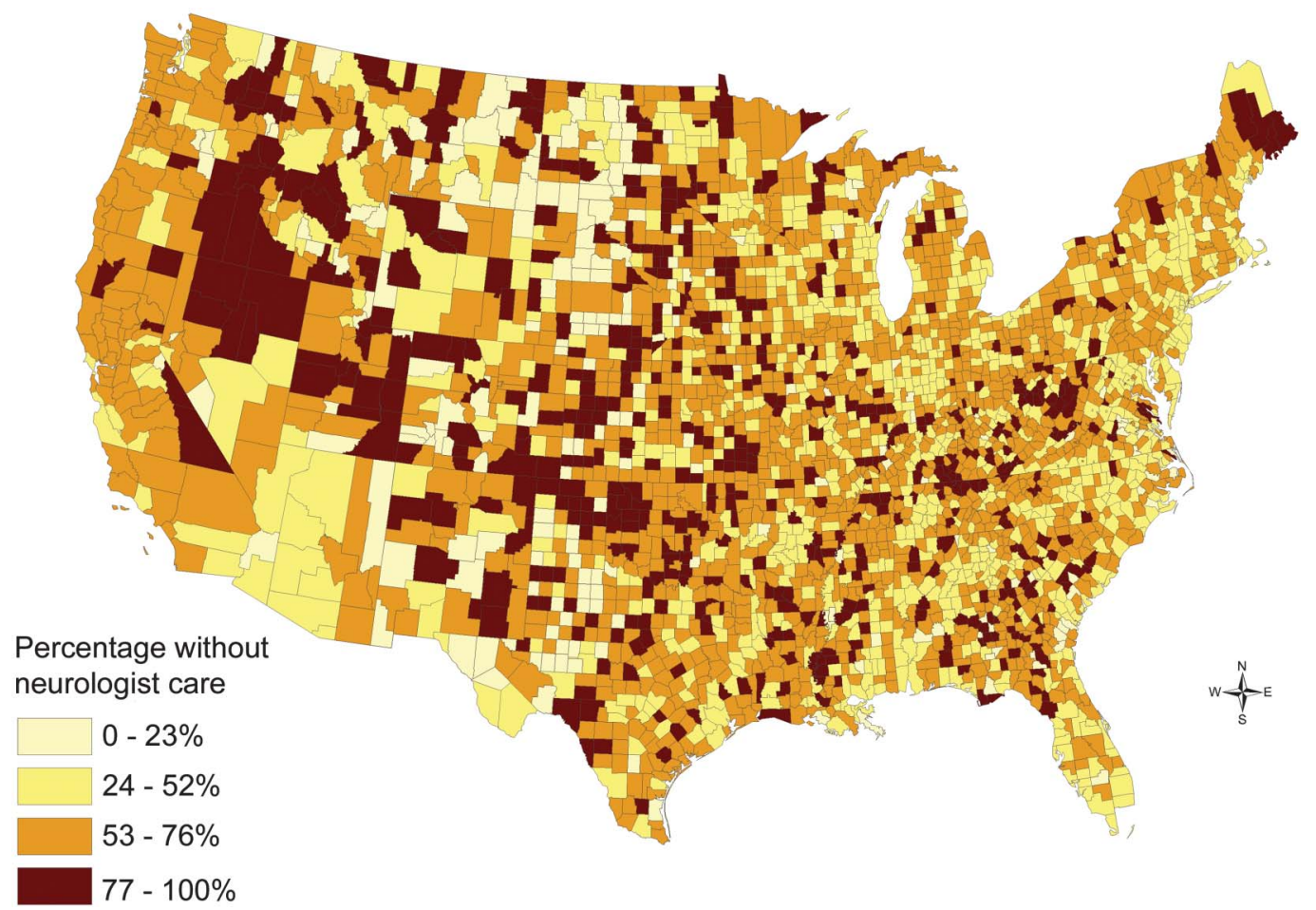

The second is that a large proportion (42\%) of Medicare beneficiaries who have been diagnosed with a common neurologic condition that benefits from neurologic care do not see a neurologist. ${ }^{3}$ The proportion seeing a neurologist in the United States appears to be comparable to that in Canada, which has fewer neurologists, and much lower than in Europe. A study in Canada found that $45 \%$ of patients with PD see a neurologist annually and $60 \%$ had seen one over 6 years. ${ }^{20}$ In Europe, a large survey of patients with PD found that $92 \%$ of respondents had seen a general neurologist and $56 \%$ had seen a PD specialist within 2 years of diagnosis. ${ }^{21}$ While several factors, including geography, supply of neurologists, referral patterns, and characteristics of respondents, can explain the differences, these studies suggest that utilization of neurologic care among individuals with PD in the United States is low and likely lower than in peer countries where reimbursement is less of an issue.

On the supply side in the United States, some neurologists appear not to be caring for Medicare beneficiaries. Because of Medicare's low reimbursement, physicians, including neurologists, may be opting out of the Medicare program. ${ }^{\mathrm{e} 2}$ While data are limited, according to a 2012 Memorandum Report from the Office of Inspector General, "[The] number of optedout physicians appears to have increased each year from 2006 to 2010." 22 The absolute number of neurologists not participating in Medicare at all is likely low ${ }^{\text {e3,e4; }}$; however, physicians may limit the number of Medicare beneficiaries with neurodegenerative conditions in their practice due to the time required and the associated low reimbursement. Lack of time and reimbursement are commonly reported reasons among primary care physicians for suboptimal care of patients with dementia. ${ }^{23}$

For those neurologists accepting Medicare, reimbursement within the program is highly skewed, such that diagnostic tests and procedures are reimbursed more than actually caring for patients (table). In one extreme example, reimbursement for a one-time imaging test that has limited utility ${ }^{\mathrm{e}}$ in the diagnosis of PD can exceed years of providing neurologic care to a patient with PD.

These counterproductive incentives can result in difficulties accessing physicians. For example, despite near universal insurance in the state, Massachusetts has reported a tight labor market for neurologists, exhibiting severe workforce shortages consistently for 3 years since $2008{ }^{\mathrm{e} 6}$ "This "shortage" is occurring in the state with the highest number of neurologists per capita. Inadequate reimbursement plagues other insurance programs, including Medicaid. ${ }^{24,25}$

\section{SUPPLY OF NEUROLOGISTS IS SUFFICIENT TO} MEET DEMAND The overall supply of physicians including neurologists is frequently cited as a cause for limited access. ${ }^{\text {e7 }}$ However, as the Massachusetts experience attests, the problem is not the absolute number of neurologists. In fact, the existing supply of neurologists is more than sufficient to meet the demand in many 


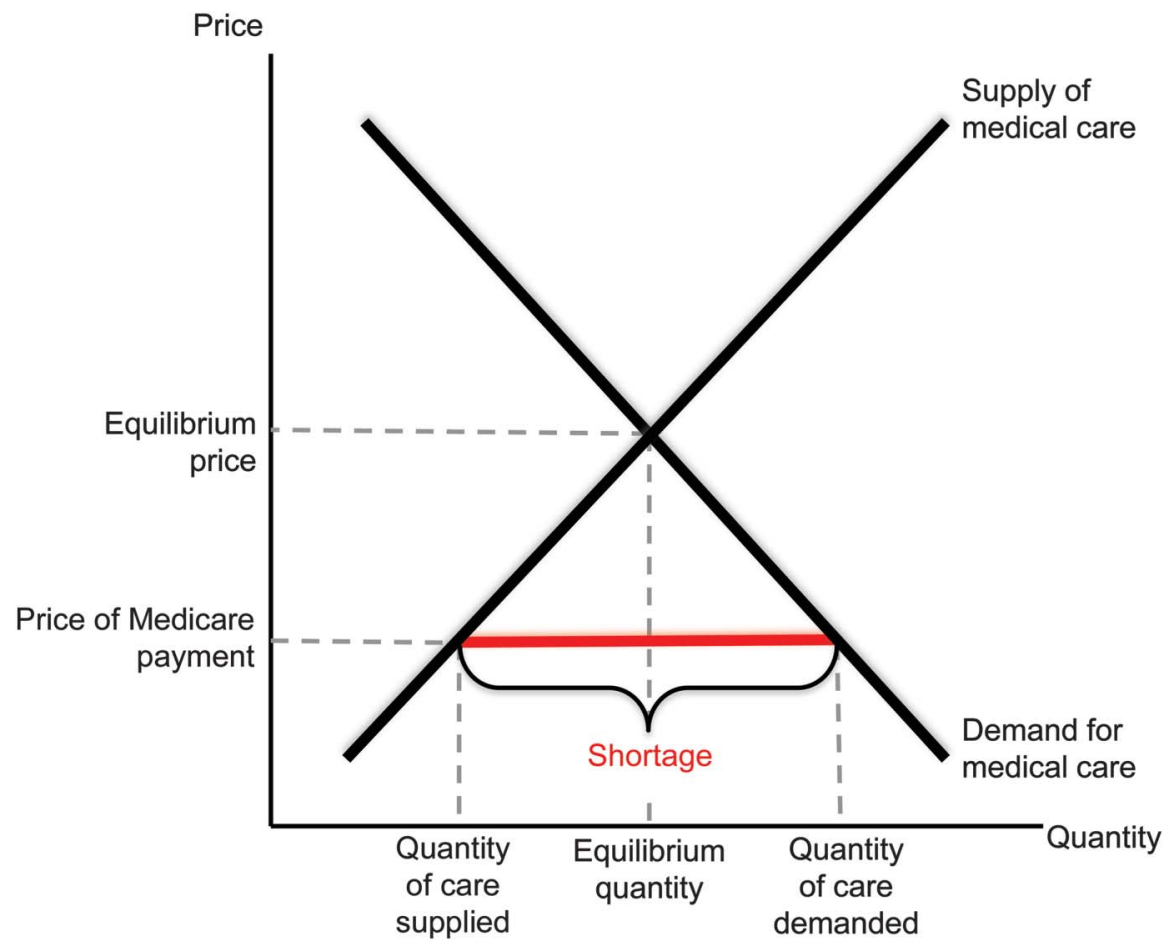

${ }^{a}$ Market equilibrium price is where the quantity of care demanded equals the quantity supplied. If Medicare's price (reimbursement) is less than the equilibrium price, the quantity of medical care demanded will be greater than the quantity of care supplied, resulting in a shortage. The magnitude of the shortage is the difference between the quantity demanded at the Medicare price and the quantity supplied at the Medicare price. ${ }^{17}$

cases, including PD. The Movement Disorders Society lists approximately 600-700 physician members seeing patients in the United States. Setting aside geographic and social considerations, this supply of neurology subspecialists is likely sufficient or nearly sufficient to care for approximately 500,000 Americans (including those under age 65) with PD. ${ }^{1}$

Beyond PD subspecialists, the overall supply of neurologists in the United States should be more than sufficient to meet the demand for most neurologic care. The number of neurologists per capita in the United States is higher than in most peer countries (figure 4). For example, the number of neurologists in the United States is 3.9 per 100,000 compared to 2.5 in Canada and 2.4 in the United Kingdom. Moreover, in the United States over the past 50 years, the neurologist density has increased more than threefold. ${ }^{13,26}$

The challenge is that current financial incentives devalue clinical care and by extension, the doctor-patient relationship. Medicare's reimbursement for chronic care is less than comparable technology-based procedures, does not cover time-intensive coordination of care, largely excludes care provided outside of an in-person physicianpatient encounter, and has fallen when adjusted for rising practice costs. ${ }^{25}$ The provision of PD care that meets the American Academy of Neurology quality measures ${ }^{27}$ requires more physician and staff time than allowed by current Medicare reimbursement guidelines. Moreover, the cost and time required to comply with Medicare's reimbursement and other policies continues to increase. ${ }^{\text {e8 }}$ Physicians operating in high-cost academic environments or in competitive community practices are increasingly disincented from caring for patients with chronic neurologic disease. The net result may be that over $40 \%$ of Medicare beneficiaries with PD do not or cannot access a neurologist, to the detriment of their health.

\section{THE SOLUTION IS NOT TO PRODUCE MORE NEUROLOGISTS BUT TO INCREASE REIMBURSEMENT FOR PATIENT CARE Aligning} incentives to reward caring for patients can offer substantial value to payors. Physician fees, especially those directed at the physician actually providing chronic care for the patient, are only a small proportion of Medicare's expenditures for these conditions. For example, in PD, reimbursement for all physician services accounts for only $26 \%$ of Medicare's expenditures, ${ }^{28}$ and that for the neurologist actually caring for the patient is only a fraction of that amount. The real cost driver for these conditions and others is paying institutions for complications of care and progression of the disease (e.g., falls, behavioral disturbances). For example, half of Medicare expenditures 


\begin{tabular}{|c|c|c|c|c|c|c|c|}
\hline Medicare's reimbursement for a sa & of commc & nly performed ne & urologic ser & ces and test & & & \\
\hline Service/procedure & CPT code & $\begin{array}{l}\text { Frequency } \\
\text { of use, } \%, 2010^{c}\end{array}$ & $\begin{array}{l}\text { Parkinson } \\
\text { disease }\end{array}$ & $\begin{array}{l}\text { Alzheimer } \\
\text { disease }\end{array}$ & $\begin{array}{l}\text { Epilepsyl } \\
\text { seizure }\end{array}$ & Stroke & Other \\
\hline \multicolumn{8}{|l|}{ Clinical care } \\
\hline New outpatient visit (level 4$)^{b}$ & 99204 & NA & $\$ 161$ & $\$ 161$ & $\$ 161$ & $\$ 161$ & $\$ 161$ \\
\hline Outpatient visit, established patient (level 4) & 99214 & NA & $\$ 104$ & $\$ 104$ & $\$ 104$ & $\$ 104$ & $\$ 104$ \\
\hline \multicolumn{8}{|l|}{$\begin{array}{l}\text { Diagnostic studies commonly performed } \\
\text { by a neurologist }{ }^{\mathrm{d}}\end{array}$} \\
\hline EEG (awake and asleep) & 95819 & 57 & NA & NA & $\$ 383 / \$ 54$ & NA & NA \\
\hline Lumbar puncture $^{b}$ & 62270 & 56 & NA & NA & $\$ 157$ & NA & NA \\
\hline EMG (2 limbs) & 95861 & 54 & NA & NA & NA & NA & $\$ 140 / \$ 79$ \\
\hline Somatosensory evoked potentials (upper limbs) & 95925 & 26 & NA & NA & NA & NA & $\$ 166 / \$ 27$ \\
\hline Continuous video EEG monitoring & 95951 & 18 & NA & NA & $\mathrm{CP} / \$ 309$ & NA & NA \\
\hline \multicolumn{8}{|l|}{$\begin{array}{l}\text { Diagnostic studies not commonly performed } \\
\text { by neurologists }{ }^{\mathrm{e}}\end{array}$} \\
\hline Sleep studies (polysomnography) & 95811 & 14 & NA & NA & NA & NA & $\$ 707 / \$ 127$ \\
\hline Brain MRI (with and without contrast) & 70553 & 10 & $\$ 658 / \$ 115$ & $\$ 658 / \$ 115$ & $\$ 658 / \$ 115$ & $\$ 658 / \$ 115$ & NA \\
\hline Carotid duplex ultrasound (bilateral) & 93880 & 10 & NA & NA & NA & $\$ 252 / \$ 30$ & NA \\
\hline Intraoperative monitoring & 95860 & 9 & NA & NA & NA & NA & $\$ 166 / \$ 107$ \\
\hline Transcranial Doppler & 93886 & 8 & NA & NA & NA & $\$ 356 / \$ 46$ & NA \\
\hline CT & 70450 & 7 & $\$ 184 / \$ 41$ & $\$ 184 / \$ 41$ & $\$ 184 / \$ 41$ & $\$ 184 / \$ 41$ & NA \\
\hline PET & 78609 & 2 & NA & NA & NA & NA & $\$ 113 / \$ 58$ \\
\hline SPECT & 78607 & 1 & $\$ 371 / \$ 58$ & $\$ 371 / \$ 58$ & NA & NA & NA \\
\hline Functional MRI & 70555 & 1 & $\mathrm{CP} / \$ 128$ & $\mathrm{CP} / \$ 128$ & $\mathrm{CP} / \$ 128$ & $\mathrm{CP} / \$ 128$ & $\mathrm{CP} / \$ 128$ \\
\hline DaTscan (ioflupane I123 injection) ${ }^{f}$ & A9584 & NA & $\$ 1,908$ & NA & NA & NA & NA \\
\hline Transthoracic echocardiogram & 93306 & NA & NA & NA & NA & $\$ 213 / \$ 65$ & NA \\
\hline
\end{tabular}

Abbreviations: $\mathrm{CP}=$ carrier priced technical component, therefore, global price is not displayed; $\mathrm{DaT}=$ dopamine transporter; $\mathrm{NA}=$ not available.

${ }^{a}$ For clinical care and nonlaboratory diagnostic tests, Medicare reimbursement was derived from the national payment amount in the 2012 CMS Physician Fee Schedule for the nonfacility price, which includes technical and professional components for those services to which the concept applies. Where applicable, global fees are listed first, followed by professional component. The global component is equal to the professional component plus the technical component. For example, an EEG (awake and asleep) is reimbursed with a global fee of $\$ 383$, with a professional component of $\$ 54$ and a technical component of $\$ 329$.

${ }^{b}$ Global (diagnostic service) or physician professional service where the professional/technical concept does not apply.

${ }^{\mathrm{c}}$ The frequency of use is the proportion of neurologists who perform this procedure within 12 months and is derived from the 2010 Practice Profile Form (Adornato et al., 2011). ${ }^{13}$

${ }^{\mathrm{d}}$ Studies performed by more than $15 \%$ of neurologists surveyed.

e Studies performed by fewer than $15 \%$ of neurologists surveyed as well as less commonly used procedures in general.

${ }^{f}$ Providers will code for A9584 and 78607 (SPECT imaging). If local Medicare Administrator Contractors cover DaTscan, a provider will be paid an amount for the SPECT imaging and a separate amount for the radiopharmaceutical DaTscan. Reimbursement for DaTscan diagnostic test is estimated at $6 \%$ plus the average sales price of $\$ 1,800$ (GE Healthcare, Waukesha, WI). ${ }^{\text {16 }}$

flow to inpatient (26\%), skilled nursing (5\%), and longterm care (19\%) facilities for PD beneficiaries. ${ }^{28}$ Beyond Medicare, Medicaid—-the largest payor for nursing care facilities - is especially at risk for the growing burden of neurodegenerative conditions that frequently result in long-term institutional care. ${ }^{29-31}$

Increasing utilization of neurologic care for neurodegenerative conditions has the potential to improve health and decrease costs. While such a hypothesis needs to be tested, the evidence suggests that improved access is at least associated with such outcomes, including decreased likelihood of nursing home placement. ${ }^{3}$ Reducing utilization of a skilled nursing facility by 1 year for one patient saves Medicaid approximately $\$ 69,000$ (assuming $\$ 200$ per day), ${ }^{28, e 9} 100$ times more than a neurologist receives for keeping a patient independent and functioning at home. In addition, beneficiaries who receive care from a neurologist are $25 \%$ less likely to be hospitalized for PD-related complications such as psychosis. ${ }^{3}$ Finally, unpublished data (from A.W.W.) indicate that Medicare beneficiaries who see a neurologist more frequently for their PD actually cost Medicare $30 \%$ less than those who do not see a neurologist.

By contrast, producing more neurologists is expensive and will not address the underlying problem. Training a new neurologist in the United States costs taxpayers-primarily through Medicare subsidies to teaching hospitals—upwards of $\$ 400,000$ just for 


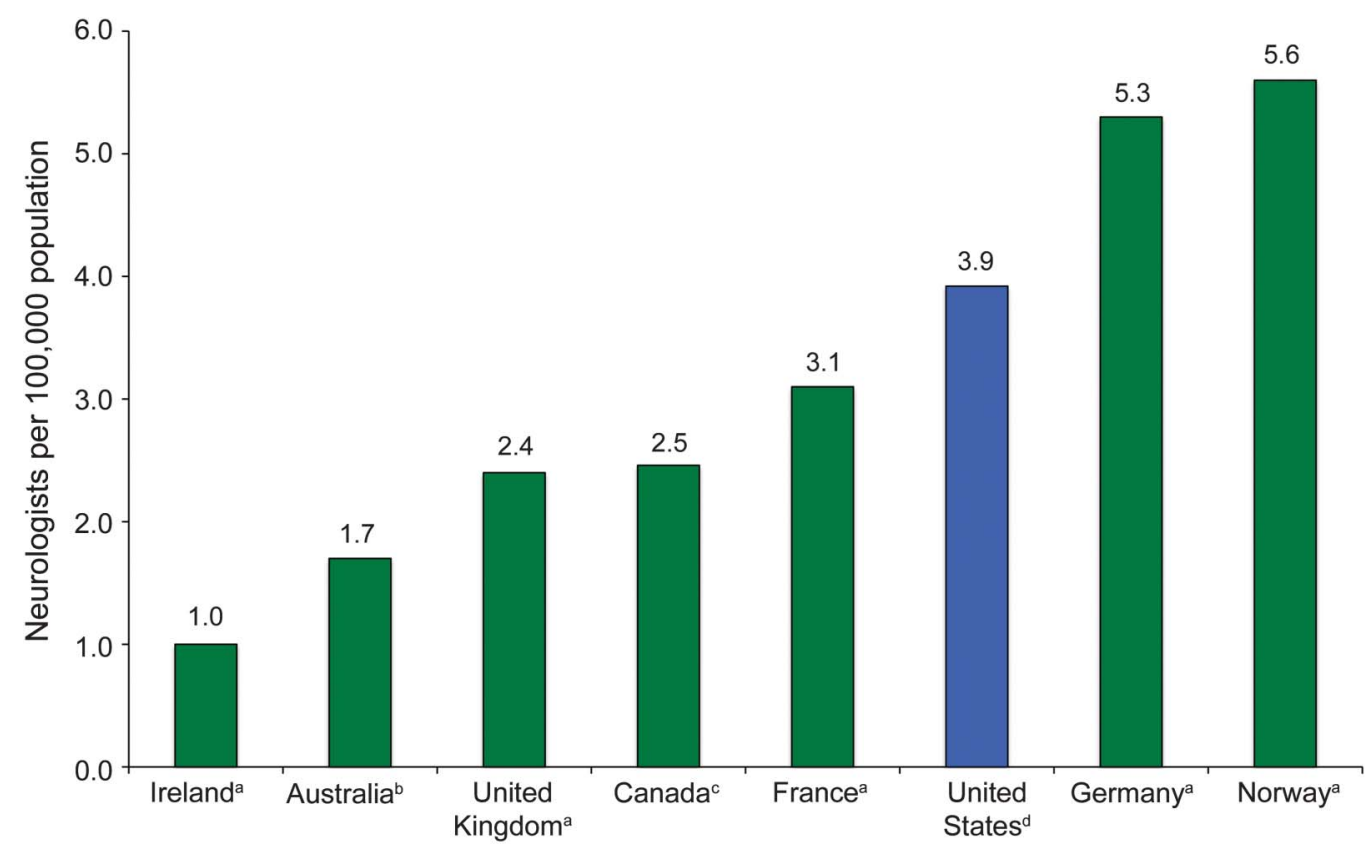

Inclusion of neurology subspecialties within these figures may vary by country; therefore, the number of neurologists per 100,000 inhabitants may not be perfectly comparable across countries. ${ }^{a}$ Neurologists per 100,000 inhabitants from

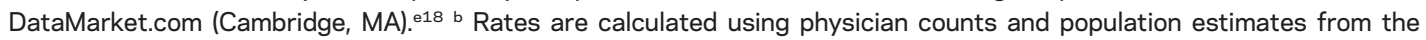
Australian Institute for Health and Welfare Medical Labour Force Survey, 2009. ${ }^{19}$ c Rates are calculated using physician counts from the Canadian Institute for Health Information and population estimates reported by the Organization for Economic and Co-operation Development in 2009. e20,e21 d Data adapted from Adornato et al., 2011.13

residency. ${ }^{32,33}$ Factoring in federally subsidized loans in college and medical school, and one newly minted neurologist could easily cost the public a half a million dollars. One hundred new neurologists per year (less than one per medical school class) would be $\$ 50$ million and excludes the considerable human capital costs.

Worse, training more neurologists would likely only have marginal benefit on increasing access. As pointed out, except in targeted areas (e.g., rural areas, underrepresented minority physicians), the United States already has a sufficient number of neurologists to care for many of the common neurologic conditions affecting Medicare beneficiaries. Moreover, the difficulty in accessing neurologic care has occurred in a setting where the number of neurologists has increased substantially. ${ }^{13}$ Finally, because of the soaring financial costs of medical education, ${ }^{\text {e10 }}$ the resulting increase in medical debt, ${ }^{\text {el1 }}$ the increasing duration of specialty training, ${ }^{13}$ and its significant opportunity costs, ${ }^{34}$ future neurologists will face even greater financial constraints and thus may be less resistant to Medicare's current incentives in caring for beneficiaries with chronic neurologic conditions.

PUBLIC ENGAGEMENT AND LEADERSHIP WILL HAVE TO DRIVE CHANGE The market solution to a shortage is to raise prices. However, rather than price increases, physicians, including neurologists, who provide care to patients with chronic conditions are operating under increasing threats to further reductions in Medicare reimbursement. ${ }^{35}$ The Affordable Care Act attempted to address the shortcomings in reimbursement by providing primary care physicians a modest $10 \%$ increase in reimbursement for caring for patients. ${ }^{33}$ However, neurologists who care for patients with chronic conditions were excluded from the policy, although currently proposed legislation aims to remedy their exclusion. ${ }^{\text {el2,el3 }}$ Larger changes in reimbursement, which could include reductions in reimbursement for overutilized services, are required that better align the financial interests of physicians with the health interests of patients. To the extent that primary care physicians may influence access to neurologists, efforts to engage public and primary carefocused organizations regarding the added value for the treatment of PD and other neurologic conditions should be developed.

With the rise in neurodegenerative conditions rapidly approaching, access to care will likely worsen. The changes that need to occur are unlikely to come from the profession, which to date has had very limited success in driving change and is viewed as self-serving in seeking changes in reimbursement for its own services. Rather, the change will likely have to occur from the public, who stands the most to gain from increased access and better care. The proportion of the public that will be affected by the access challenge will increase as both patients and their families seek to receive the care that they 
need and desire. Already 2.9 million households are affected by Alzheimer disease. ${ }^{\mathrm{e} 9}$ Moreover, increased access to specialists could benefit beneficiaries with other chronic neurologic or medical conditions. ${ }^{36}$

The public can help drive changes that over time can improve its access to needed neurologic care. In the short term, the public, including patient advocacy groups, can argue for aligning financial incentives with their health needs. Such an approach made a modest difference for primary care and could do the same for neurology. However, to ensure longer-term support for caring for patients with chronic conditions, more fundamental changes in the system will be needed.

Currently, Medicare reimbursement rates are heavily influenced by the Relative Value Scale Update Committee organization by the American Medical Association. ${ }^{37}$ The committee is a nonrepresentative group of physicians charged with assigning relative value units that underlie Medicare reimbursement for every covered product and service. The committee, which gives equal representation to small specialties (e.g., vascular surgery) as to large ones (e.g., pediatrics), has been criticized for supporting Medicare reimbursement policies that support technology or procedure-based interventions at the expense of cognitive-based interventions, including simply caring for patients. ${ }^{37}$ The rationale for having a skewed sample of physicians set reimbursement policy for a taxpayer-financed health insurance program is not clear. What is increasingly clear is that the system is not serving the public's interests. Greater public participation, including potentially public leadership, is needed to stem the self-serving factions that are increasingly plaguing the Relative Value Scale Update Committee and to ensure that its policies are directed to the interests of the beneficiaries that it serves rather than the self-interests of select providers.

Longer-term, alternative health care delivery models that meet the needs of patients and are supported by empirical evidence demonstrating both their feasibility and value could have even greater impact on increasing access and improving care. Chronic care models, including patient-centered medical homes, have potential to improve outcomes for asthma, congestive heart failure, depression, and diabetes, ${ }^{38}$ but evidence for their benefit in caring for individuals with chronic neurodegenerative conditions is generally lacking and largely limited to dementia care. ${ }^{39,40}$ Technology, including telemedicine, can help reduce geographical barriers to care, but restrictive reimbursement and arcane licensure requirements are hindering their broader adoption. The public can advocate for policy changes supporting alternative models that better meet their needs.

Over the last generation, the public has a successful track record in directing change in research priorities, whether it was for HIV in the $1980 \mathrm{~s}^{\mathrm{e} 14}$ or more recently for Alzheimer disease. ${ }^{\mathrm{e} 15}$ Such engagement helped lead to the transition of a rapidly progressive and fatal condition to a chronic one. That same advocacy can now be directed toward how society directs health care funds in this country. For too long, the public has been silent on how its tax dollars are spent for health care and consequently, those funds have not always been directed in its interests. The coming crisis in care for the growing number of individuals with neurodegenerative conditions is an opportune time to end that silence.

\section{AUTHOR CONTRIBUTIONS}

Dr. Dorsey had full access to all the data in the study and takes responsibility for the integrity of the data and the accuracy of the data analysis. Drafting/revising the manuscript for content, including medical writing for content: E.R. Dorsey, B.P. George, B. Leff, A.W. Willis. Study concept or design: E.R. Dorsey. Analysis or interpretation of data: E.R. Dorsey, B.P. George, B. Leff, A.W. Willis. Acquisition of data: E.R. Dorsey, B.P. George, A.W. Willis. Study supervision or coordination: E.R. Dorsey.

\section{ACKNOWLEDGMENT}

The authors thank Amanda Becker, Director of Medical Economics at the American Academy of Neurology, for guidance in determining reimbursement for neurologic services and procedures and Dr. Emily Oster, Associate Professor of Economics at The University of Chicago Booth School of Business, for economic review.

\section{STUDY FUNDING}

No targeted funding reported.

\section{DISCLOSURE}

E.R. Dorsey has received compensation for consulting activities from Lundbeck, Medtronic, and the National Institute of Neurological Disorders and Stroke; research support from Google, Lundbeck, Prana Biotechnology, Macklin Foundation, Robert Wood Johnson Foundation, and the Agency for Health Care Research and Quality (HS018960-01); stock options from consultingMD; and compensation for expert testimony. B. George conducts research funded by the Parkinson's Disease Foundation (Summer Student Fellowship No. PDF-SFW-1204) and has previously received research funding from the American Academy of Neurology, National Institute on Aging, and New York Academy of Medicine. B. Leff receives a portion of fees from Johns Hopkins University for licensing or consulting arrangements related to the Hospital at Home care model with Mobile Doctors 24/7 International and Clinically Home LLC. The terms of this arrangement are managed by the Johns Hopkins University in accordance with its conflict-of-interest policies. Dr. Leff is a noncompensated board member and president of the American Academy of Home Care Medicine, noncompensated member of the Board of Regents of the American College of Physicians, noncompensated member of the Board of Directors of the Alliance for Home Health Quality and Innovation, and noncompensated member of the Research Board of the Kendal Corporation. He is a compensated member of the strategic advisory board of the Amedisys Corporation. He is a recipient of grants from the John A. Hartford Foundation, Agency for Healthcare Research and Quality, The Atlantic Philanthropies, and the National Institute of Aging, the National Quality Forum. A.W. Willis reports no disclosures. Her research support in the past 5 years has been solely from the National Institutes of Health, the St. Louis Chapter of the American Parkinson's Disease Association, and Washington University School of Medicine. Go to Neurology.org for full disclosures.

Received August 15, 2012. Accepted in final form January 22, 2013.

\section{REFERENCES}

1. Dorsey ER, Constantinescu R, Thompson JP, et al. Projected number of people with Parkinson disease in the most populous nations, 2005 through 2030. Neurology 2007;68: 384-386. 
2. Hebert LE, Scherr PA, Bienias JL, Bennett DA, Evans DA. Alzheimer disease in the US population: prevalence estimates using the 2000 census. Arch Neurol 2003;60:1119-1122.

3. Willis AW, Schootman M, Evanoff BA, Perlmutter JS, Racette BA. Neurologist care in Parkinson disease: a utilization, outcomes, and survival study. Neurology 2011;77:851-857.

4. Burke JF, Albin RL. Do neurologists make a difference in Parkinson disease care? Neurology 2011;77:e52-e53.

5. Willis AW, Schootman M, Tran R, et al. Neurologistassociated reduction in PD-related hospitalizations and health care expenditures. Neurology 2012;79:1774-1780.

6. Cheng EM, Swarztrauber K, Siderowf AD, et al. Association of specialist involvement and quality of care for Parkinson's disease. Move Disord 2007;22:515-522.

7. Dorsey ER, Voss TS, Shprecher DR, et al. A U.S. survey of patients with Parkinson's disease: satisfaction with medical care and support groups. Mov Disord 2010;25:2128-2135.

8. Schatz M, Zeiger RS, Mosen D, et al. Improved asthma outcomes from allergy specialist care: a population-based cross-sectional analysis. J Allergy Clin Immunol 2005;116: 1307-1313.

9. Ezekowitz JA, van Walraven C, McAlister FA, Armstrong PW, Kaul P. Impact of specialist follow-up in outpatients with congestive heart failure. CMAJ 2005;172:189-194.

10. Zgibor JC, Songer TJ, Kelsey SF, Drash AL, Orchard TJ. Influence of health care providers on the development of diabetes complications: long-term follow-up from the Pittsburgh Epidemiology of Diabetes Complications Study. Diabetes Care 2002;25:1584-1590.

11. Aday LA, Andersen R. A framework for the study of access to medical care. Health Serv Res 1974;9:208-220.

12. Donabedian A. Aspects of Medical Care Administration: Specifying Requirements for Health Care. Published for the Commonwealth Fund by Harvard University Press. Cambridge: Harvard University Press; 1973.

13. Adornato BT, Drogan O, Thoresen P, et al. The practice of neurology, 2000-2010: report of the AAN Member Research Subcommittee. Neurology 2011;77:1921-1928.

14. Dahodwala N, Xie M, Noll E, Siderowf A, Mandell DS. Treatment disparities in Parkinson's disease. Ann Neurol 2009;66:142-145.

15. Swarztrauber K, Vickrey BG. Do neurologists and primary care physicians agree on the extent of specialty involvement of patients referred to neurologists? J Gen Intern Med 2004;19:654-661.

16. Callahan CM, Boustani MA, Unverzagt FW, et al. Effectiveness of collaborative care for older adults with Alzheimer disease in primary care: a randomized controlled trial. JAMA 2006;295:2148-2157.

17. Andrulis DP. Access to care is the centerpiece in the elimination of socioeconomic disparities in health. Ann Intern Med 1998;129:412-416.

18. Stevens R. Medicare and the American Social Contract. Washington, DC: National Academy of Social Insurance; 1999.

19. Newhouse JP, Manning WG, Morris CN, et al. Some interim results from a controlled trial of cost sharing in health insurance. N Engl J Med 1981;305:1501-1507.

20. Guttman M, Slaughter PM, Theriault ME, DeBoer DP, Naylor CD. Parkinsonism in Ontario: physician utilization. Can J Neurol Sci 2002;29:221-226.

21. Bloem BR, Stocchi F. Move for change part I: a European survey evaluating the impact of the EPDA Charter for
People with Parkinson's disease. Eur J Neurol 2012;19: 402-410.

22. Wright S. Memorandum Report: Lack of Data Regarding Physicians Opting Out of Medicare. Report No.: OEI-0711-00340. Washington, DC: Department of Health and Human Services; 2012.

23. Fortinsky RH, Zlateva I, Delaney C, Kleppinger A. Primary care physicians' dementia care practices: evidence of geographic variation. Gerontologist 2010;50:179-191.

24. Galbraith AA, Grossman DC, Koepsell TD, Heagerty PJ, Christakis DA. Medicaid acceptance and availability of timely follow-up for newborns with Medicaid. Pediatrics 2005;116:1148-1154.

25. Pham HH, Ginsburg PB. Unhealthy trends: the future of physician services. Health Aff2007;26:1586-1598.

26. Menken M. The coming oversupply of neurologists in the 1980s. Implications for neurology and primary care. JAMA 1981;245:2401-2403.

27. Cheng EM, Tonn S, Swain-Eng R, Factor SA, Weiner WJ, Bever CT Jr. Quality improvement in neurology: AAN Parkinson disease quality measures: report of the Quality Measurement and Reporting Subcommittee of the American Academy of Neurology. Neurology 2010;75: 2021-2027.

28. Noyes K, Liu H, Li Y, Holloway R, Dick AW. Economic burden associated with Parkinson's disease on elderly Medicare beneficiaries. Mov Disord 2006;21:362-372.

29. Mitchell SL, Kiely DK, Kiel DP, Lipsitz LA. The epidemiology, clinical characteristics, and natural history of older nursing home residents with a diagnosis of Parkinson's disease. J Am Geriatr Soc 1996;44:394-399.

30. Aarsland D, Larsen JP, Tandberg E, Laake K. Predictors of nursing home placement in Parkinson's disease: a populationbased, prospective study. J Am Geriatr Soc 2000;48:938-942.

31. Eaker ED, Vierkant RA, Mickel SF. Predictors of nursing home admission and/or death in incident Alzheimer's disease and other dementia cases compared to controls: a population-based study. J Clin Epidemiol 2002;55:462-468.

32. Dorsey ER, Nicholson S, Frist WH. Commentary: improving the supply and distribution of primary care physicians. Acad Med 2011;86:541-543.

33. Iglehart JK. Health reform, primary care, and graduate medical education. N Engl J Med 2010;363:584-590.

34. Dorsey ER, Nincic D, Schwartz JS. An evaluation of four proposals to reduce the financial burden of medical education. Acad Med 2006;81:245-251.

35. Iglehart JK. Medicare payment reform: proposals for paying for an SGR repeal. N Engl J Med 2011;365:1859-1861.

36. Wagner EH, Austin BT, Von Korff M. Organizing care for patients with chronic illness. Milbank Q 1996;74:511-544.

37. Goodson JD. Unintended consequences of resource-based relative value scale reimbursement. JAMA 2007;298:2308-2310.

38. Tsai AC, Morton SC, Mangione CM, Keeler EB. A metaanalysis of interventions to improve care for chronic illnesses. Am J Manag Care 2005;11:478-488.

39. Chodosh J, Pearson ML, Connor KI, et al. A dementia care management intervention: which components improve quality? Am J Manag Care 2012;18:85-94.

40. Vickrey BG, Mittman BS, Connor KI, et al. The effect of a disease management intervention on quality and outcomes of dementia care: a randomized, controlled trial. Ann Intern Med 2006;145:713-726. 